The Canadian Mineralogist

Vol. 38, pp. 1283-1294 (2000)

\title{
AN ALGORITHM FOR THE TRANSFORMATION OF XRF IMAGES INTO MINERAL-DISTRIBUTION MAPS
}

\author{
SHOJI TOGAMI ${ }^{\S}$, MASAO TAKANO AND MINEO KUMAZAWA \\ Department of Earth and Planetary Sciences, Nagoya University, Nagoya, 464-8602, Japan
}

KATSUYOSHI MICHIBAYASHI

Institute of Geosciences, Shizuoka University, Shizuoka, 422-8529, Japan

\begin{abstract}
A new numerical method has been developed that uses the pixel-intensities from X-ray fluorescence (XRF) images to produce mineral-distribution images or maps. The XRF images are obtained using a scanning X-ray analytical microscope (SXAM); the derived mineral-distribution maps can be applied to study the petrographic characterization of a rock or ores. As a test case, we applied this method to a granite consisting dominantly of quartz, biotite, plagioclase and K-feldspar. Maps of the major elements, including $\mathrm{Al}, \mathrm{Si}, \mathrm{K}, \mathrm{Ca}$ and $\mathrm{Fe}$, were obtained with the SXAM. XRF intensity is recorded for each element on a $256 \times$ 256 pixel map. To transform these element-distribution maps into mineral-distribution maps, we employed the maximum likelihood method for a Gaussian distribution, i.e., a least-squares method. The coefficient between XRF intensity and the proportion of a desired mineral was determined from the average value in a few hundred pixels that record the XRF intensity of the desired mineral in isolation. Where one pixel recorded XRF intensity for more than one mineral, its intensity was assumed to have a linear relationship with the composition of the minerals included in the pixel. The proposed least-squares method is an alternative technique to methods using purely image-analysis operations, such as image enhancements, erosions, dilations and image Boolean operations. Experiments with the granite sample showed that the least-squares method gives appropriate mineral-distribution maps if the acquisition time for the XRF maps is sufficiently long, e.g., 48 hours for the granite. The sources of errors in the calculated proportions of the minerals are related to fluctuations of X-ray intensities and variations of chemical composition in each mineral. A method is also proposed to estimate these errors.
\end{abstract}

Keywords: granite, least-squares method, mineral-distribution map, scanning X-ray analytical microscope, XRF image.

SOMMAIRE

Nous avons développé une nouvelle méthode numérique fondée sur l'intensité des pixels contenant les images de fluorescence $\mathrm{X}$ pour produire des images ou des cartes de la distribution de minéraux. Les images de la fluorescence $\mathrm{X}$ sont obtenues avec un microscope analytique à balayage de rayons X. Les cartes dérivées montrant la distribution de minéraux peuvent servir à la caractérisation pétrographique d'une roche ou d'un minerai. Nous avons appliqué cette méthode à l'étude d'un granite contenant surtout quartz, biotite, plagioclase et feldspath potassique. Des cartes de la distribution des éléments majeurs, dont $\mathrm{Al}$, $\mathrm{Si}, \mathrm{K}, \mathrm{Ca}$ et $\mathrm{Fe}$, ont été préparées selon l'intensité de la fluorescence $\mathrm{X}$ de chaque élément enregistrée avec le microscope analytique et projetée sur une carte de $256 \times 256$ pixels. Afin de transformer ces cartes de distribution d'éléments en cartes illustrant la distribution de minéraux, nous employons la méthode de la probabilité maximum pour une distribution gaussienne, c'est-à-dire, une méthode par moindres carrés. Le coefficient de concordance entre l'intensité de la fluorescence X et la proportion d'un minéral désiré est fixé selon la valeur moyenne de quelques centaines de pixels qui enregistrent l'intensité du minéral désiré en isolation. Dans les cas où il y a dans un pixel des intensités de fluorescence X pour plus d'un minéral, nous attribuons l'intensité à chaque minéral selon une relation linéaire avec la composition des minéraux inclus dans ce pixel. La méthode de moindres carrés que nous proposons offre une alternative aux méthodes qui résultent des seules opérations d'analyses d'image, par exemple l'accroissement des images, les érosions, les dilatations, et les opérations booléennes. Nos expériences avec l'échantillon de granite démontrent que la méthode des moindres carrés donne des cartes raisonnables de la distribution des minéraux si le temps d'acquisition est suffisamment long, c'est-à-dire, 48 heures dans la cas du granite. Les sources d'erreurs dans les proportions calculées des minéraux sont liées aux fluctuations des intensités des rayons $\mathrm{X}$ et aux variations dans la composition chimique de chaque minéral. Nous proposons une méthode pour évaluer ces sources d'erreur.

(Traduit par la Rédaction)

Mots-clés: granite, méthode de moindres carrés, carte de distribution de minéraux, microscope analytique à balayage de rayons X, image de fluorescence $X$.

§ E-mail address: togami@eps.nagoya-u.ac.jp 


\section{INTRODUCTION}

A major problem encountered in analyzing digital images of planar sections of rocks is the recognition and separation of minerals. A back-scattered electron (BSE) image and elemental X-ray map(s) are most commonly analyzed in image processing. The BSE image can be acquired with a scanning electron microscope (SEM) in a short time. The image can be used to distinguish minerals on the basis of differences in BSE intensity, which is strongly dependent on the average atomic number of the target (Robinson \& Nickel 1979, Hall \& Lloyd 1981, Pye 1984, Dilks \& Graham 1985, Petruk 1988, 1989, Lastra et al. 1998).

An elemental X-ray map is usually acquired with a SEM interfaced with an energy-dispersion X-ray spectrometer (EDX) or an electron probe micro-analyzer (EPMA) interfaced with a wavelength-dispersion X-ray spectrometer. Although it takes a longer time to acquire the X-ray map than the BSE image, the X-ray map or the X-ray counts are needed to discriminate minerals with overlapping grey levels in the BSE image. There are image-analysis methods that use X-ray maps or Xray signals to discriminate between mineral with same BSE grey level (e.g., Lastra et al. 1998). Alternatively, principal component analysis has been used with X-ray maps to distinguish different minerals (Tsuchiyama et al. 1991, Launeau et al. 1994). However, the area of measurement in an SEM-EDX analysis or EPMA is limited $\left(c a .100 \mathrm{~cm}^{2}\right)$ even when combining fields with the SEM-EDX or by stage-scanning with the EPMA. Therefore, these instruments are not adequate when a larger area is studied, particularly of rocks consisting of coarse-grained minerals, such as granite.

Optical images (grey-scale images or RGB images) have been utilized for larger areas (Hayashi \& Suzuki 1990, Launeau et al. 1994, Nishimoto 1996, Ikeda et al. 1997). These images are acquired with a digital camera, a video camera or an image scanner, among other devices. They have some advantages, such as easy usage. However, mineral recognition by analysis of an optical image is less accurate than by X-ray maps, since the optical image usually displays more significant overlaps in grey-level ranges or three-channel (red, green, blue) ranges in brightness corresponding to the different minerals.

In this study, we utilized X-ray fluorescence images acquired with a scanning X-ray analytical microscope (SXAM). As described below, the SXAM can acquire elemental X-ray maps of similar or better quality compared to those acquired by the SEM-EDX or the EPMA, but the field of view of the SXAM is larger (maximum of $200 \times 200 \mathrm{~mm}$ ).

In conventional image-processing, a single-channel image histogram (BSE images or single-element X-ray images) may be directly thresholded to separate mineral species. However, minerals commonly overlap in the histogram of single-channel images, and thus direct thresholding is not possible to separate those minerals (Launeau et al. 1994). Chiaruttini et al. (1999) have developed methods to enhance the separation of minerals with slight overlaps in the BSE image. However, the problem still persists for minerals with strong overlaps in the BSE image. There are other methods to separate minerals that use an EPMA in combination with BSE image segmentation, enhanced unthresholded X-ray maps, X-ray counts and conventional image Boolean operations (e.g., Petruk 1989, Lastra et al. 1998, Wilson \& Lastra 1999). Also there are methods that use SEM, multiple EDX detectors and dedicated hardware to separate minerals (Miller et al. 1982). We present a new least-squares method that does not require thresholding and is an alternative technique to methods using exclusively image-analysis operations. The method has been developed for an ordinary personal computer (e.g., CPU: Intel Pentium II 266MHz, RAM: $64 \mathrm{MB}$, OS: Microsoft Windows 98) commonly available in any university and laboratory. The algorithm and validity will be shown with experiments.

\section{INSTRUMENTATION}

The X-ray analytical microscope used in this study, made by Horiba Ltd., model XGT-2000V, was described by Hosokawa et al. (1997) and Michibayashi et al. (1999). Continuous X-rays (Rh anode, $50 \mathrm{kV}, 1 \mathrm{~mA}$ ) are guided onto a sample with an X-ray guide tube, whose inner diameter is $100 \mu \mathrm{m}$, producing a finely focused and high-intensity X-ray beam.

Fluorescence $\mathrm{X}$-rays from the sample are detected with an hp-Si detector in an energy-dispersion X-ray spectrometer. The sample is placed on an $x-y$ scanning table, so that thirty-one two-dimensional images corresponding to element-distribution maps are acquired simultaneously. A slightly rough surface on the sample has no effect on the image because of the large solid angle of the hp-Si detector. Consequently, sample preparation is very easy, as the sample surface is only polished with abrasive \#600 to \#800 in size.

The most important feature of the SXAM is that the sample is located outside a vacuum chamber. Thus, operations such as changing samples are easy. However, elements lighter than aluminum cannot be detected, as the thin layer of air between the chamber and the sample absorbs soft X-rays.

Each X-ray map has a fixed number of pixels (i.e., $256 \times 256$ ), regardless of magnification. The value of each pixel indicates the number of X-ray photons counted in the area of the pixel. The field of view has a maximum area of $200 \times 200 \mathrm{~mm}$ (the area represented by each pixel is $0.8 \times 0.8 \mathrm{~mm}$ ) and a minimum area of $2.56 \times 2.56 \mathrm{~mm}$ (each pixel is $0.01 \times 0.01 \mathrm{~mm}$ ).

Results from the SXAM can be compared with those from other instruments. X-ray maps acquired with a SEM-EDX or an EPMA may be as time-consuming as the SXAM, specifically when a SEM-EDX or an EPMA 
is operated to maximize the field of view, by combining fields or stage scanning, respectively. However, these instruments have a smaller field of view than the SXAM. RGB images acquired with an image scanner can be obtained quickly, and its field of view is large, but the number of measured parameters is smaller than the SXAM. The SXAM enables many parameters to be obtained with a field of view comparable to the optical images, though measurement is time-consuming. Operation times for the SEM-EDX or EPMA are restricted because the surface of the sample is charged by the electron beam. In contrast, the time for SXAM analyses is unrestricted, and it is possible to use longer-duration analyses to obtain good signal-to-noise ratios. Finally, although SXAM analysis is time-consuming, the operation is fully automatic.

\section{Measurement with the SXAM}

In this paper, we used a medium-grained biotite granite from Teshima in the Shiwaku Islands, southwestern Japan, located in the Ryoke high-temperature low-pressure metamorphic belt (Arita 1988, Michibayashi et al. 1999). The granite consists mainly of quartz, plagioclase, K-feldspar, and biotite, with an average grainsize of about $0.5 \mathrm{~mm}$ (for quartz, K-feldspar and plagioclase), and includes minor minerals, such as zircon and muscovite. In addition, chemical analysis by EPMA showed that the plagioclase grains are $\mathrm{An}_{5-16}$, the $\mathrm{K}$ feldspar grains are $\mathrm{Or}_{92-96}$, and the biotite grains consist of annite with $\mathrm{Mg} /(\mathrm{Fe}+\mathrm{Mg})$ in the range 0.05-0.07.

The SXAM was set to acquire X-ray fluorescence (XRF) images for $\mathrm{Al}, \mathrm{Si}, \mathrm{K}, \mathrm{Ca}$ and Fe among the elements present in the minerals. The polished slab used has a thickness of about $15 \mathrm{~mm}$. We set the field of view to $24.6 \times 24.6 \mathrm{~mm}$ (the area represented by each pixel was $96 \times 96 \mu \mathrm{m})$, which is the size of an ordinary thin section. We then acquired a series of XRF images with operation times of 16, 32, 48, 64 and 80 hours, respectively, without any dead time.

\section{Acquired XRF images}

Figure 1 shows XRF images obtained from a 48-hour analysis. The measured value of each pixel in the elemental X-ray maps represents the number of X-ray photons with energy near each $K \alpha_{1}$ line (energy window from $K \alpha_{1}-0.10$ to $K \alpha_{1}+0.09 \mathrm{keV}$ ).

The Al map shows the distribution of all minerals except quartz, which is devoid of Al. Contrasting this map with the Si map reveals the distribution of quartz. The K map represents the distribution of K-feldspar and annite, but the K-feldspar regions are more obvious than the annite regions. Also, the Fe map represents the distribution of annite, the only host of Fe.

The Ca map shows that $\mathrm{Ca}$ is found also where plagioclase does not occur. Such regions are coincident with the distribution of $\mathrm{K}$. This situation arises because the photons originally having the energy of $K \beta$ line of $\mathrm{K}$ are counted within the $\mathrm{Ca}$ energy window, since the energy of $K \beta_{1}$ line of $\mathrm{K}(3.59 \mathrm{keV})$ is close to the energy of $K \alpha_{1}$ line of $\mathrm{Ca}(3.31 \mathrm{keV})$. In this study, we present an algorithm that enables us to analyze such an elemental map.

\section{TRANSFORMATION OF XRF IMAGeS to Mineral-Distribution MAPS}

\section{Observation equations}

The following method was used to transform the XRF images into the mineral-distribution maps. The measured intensities in five XRF images ( $\mathrm{Al}, \mathrm{Si}, \mathrm{K}, \mathrm{Ca}$ and $\mathrm{Fe}$ ) on a certain pixel were defined as $\mathrm{x}_{1}, \mathrm{x}_{2}, \mathrm{x}_{3}, \mathrm{x}_{4}$ and $x_{5}$, respectively. Then, area proportions of four minerals (quartz, plagioclase, K-feldspar and annite) on the same pixel, which are equivalent to volume proportion of the minerals if enough grains were measured, were defined as $\mathrm{m}_{1}, \mathrm{~m}_{2}, \mathrm{~m}_{3}$ and $\mathrm{m}_{4}$, respectively. We emphasize that the main purpose in this analysis is to derive $\mathrm{m}_{j}(j=1,2,3,4)$ from $\mathrm{x}_{i}(i=1,2,3,4,5)$.

Here, we make the following assumptions. Firstly, the chemical composition of each mineral is fixed. Secondly, the amount of fluorescence X-ray photons detected within each energy-window is related linearly to volume proportions of minerals. For instance, the amount of the fluorescence X-ray within the Si energy window $\left(\mathrm{Si}_{\mathrm{XRF}}\right)$ would be represented as

$$
\mathrm{Si}_{\mathrm{XRF}}=\mathrm{a}_{1} \mathrm{~m}_{1}+\mathrm{a}_{2} \mathrm{~m}_{2}+\mathrm{a}_{3} \mathrm{~m}_{3}+\mathrm{a}_{4} \mathrm{~m}_{4}
$$

where $\mathrm{a}_{1}, \mathrm{a}_{2}, \mathrm{a}_{3}$ and $\mathrm{a}_{4}$ are coefficients determined at the conditions of measurement. In reality, such values as $\mathrm{Si}_{\mathrm{XRF}}$ should be corrected for the matrix effect. However, the method shown here works approximately even if equation (1) is used. Thirdly, the number of X-ray photons except for fluorescence X-rays (hereafter called background X-rays) detected within each energy-window is also related linearly to the volume proportion of minerals. For instance, the amount of the background $\mathrm{X}$-rays within the $\mathrm{Si}$ energy-window $\left(\mathrm{Si}_{\mathrm{bg}}\right)$ would be represented as

$$
\mathrm{Si}_{\mathrm{bg}}=\mathrm{b}_{1} \mathrm{~m}_{1}+\mathrm{b}_{2} \mathrm{~m}_{2}+\mathrm{b}_{3} \mathrm{~m}_{3}+\mathrm{b}_{4} \mathrm{~m}_{4},
$$

where $b_{1}, b_{2}, b_{3}$ and $b_{4}$ are coefficients determined at the conditions of measurement. The background X-rays result from several factors. Some result from the chemical composition of the sample; indeed, this is the mineral composition if the first assumption holds, e.g., Compton scattering inside the sample, influence of closely spaced X-ray peaks, sum peak, escape peak, and so on. Some factors would have no relation to the chemical composition of the sample, e.g., Compton scattering inside the detector, diffracted X-rays that will occur only if the arrangement among the primary $\mathrm{X}$-rays, the 


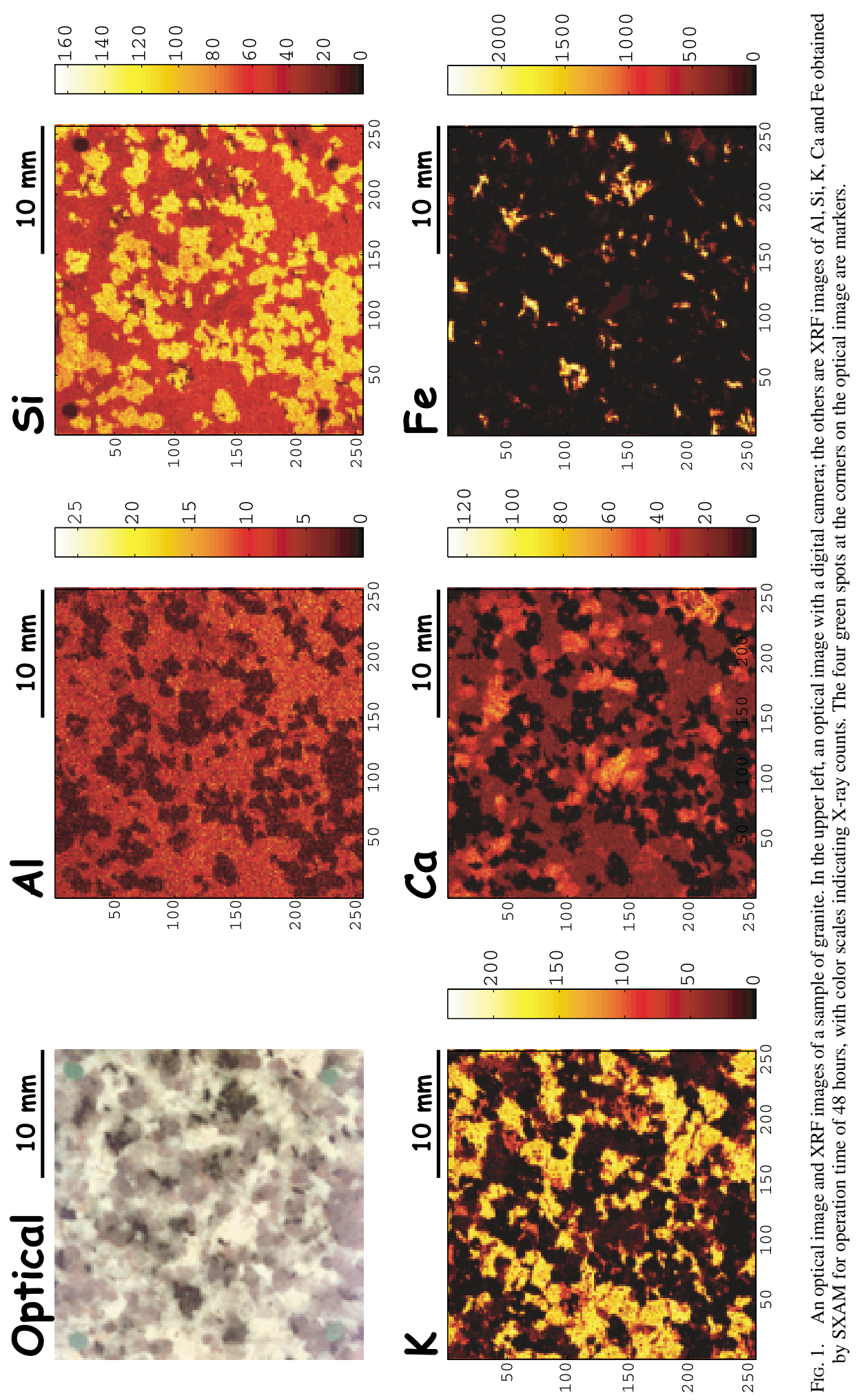


sample and the detector satisfies Bragg's law by accident, and so on; we neglected these factors. Background $\mathrm{X}$-rays contribute little to the $\mathrm{X}$-ray-fluorescence analysis (in case of $\mathrm{Si}, 2-3 \%$ of the total).

By making the above assumptions, the equation relating the measured values $\left(\mathrm{x}_{i}\right)$ to the volume proportions of minerals $\left(\mathrm{m}_{j}\right)$ was represented in case of $\mathrm{Si}$ (i.e., $\mathrm{x}_{2}$ ) as

$$
\begin{aligned}
& \mathrm{x}_{2}=\mathrm{Si}_{\mathrm{XRF}}+\mathrm{Si}_{\mathrm{bg}}=\mathrm{A}_{1} \mathrm{~m}_{1}+ \\
& \mathrm{A}_{2} \mathrm{~m}_{2}+\mathrm{A}_{3} \mathrm{~m}_{3}+\mathrm{A}_{4} \mathrm{~m}_{4},
\end{aligned}
$$

where $\mathrm{A}_{i}=\mathrm{a}_{i}+\mathrm{b}_{i}(i=1,2,3,4)$. All the equations were finally unified as

$$
\left(\begin{array}{l}
\mathrm{x}_{1} \\
\mathrm{x}_{2} \\
\mathrm{x}_{3} \\
\mathrm{x}_{4} \\
\mathrm{x}_{5}
\end{array}\right)=\left(\begin{array}{llll}
\mathrm{A}_{11} & \mathrm{~A}_{12} & \mathrm{~A}_{13} & \mathrm{~A}_{14} \\
\mathrm{~A}_{21} & \mathrm{~A}_{22} & \mathrm{~A}_{23} & \mathrm{~A}_{24} \\
\mathrm{~A}_{31} & \mathrm{~A}_{32} & \mathrm{~A}_{33} & \mathrm{~A}_{34} \\
\mathrm{~A}_{41} & \mathrm{~A}_{42} & \mathrm{~A}_{43} & \mathrm{~A}_{44} \\
\mathrm{~A}_{51} & \mathrm{~A}_{42} & \mathrm{~A}_{43} & \mathrm{~A}_{54}
\end{array}\right) \cdot\left(\begin{array}{l}
\mathrm{m}_{1} \\
\mathrm{~m}_{2} \\
\mathrm{~m}_{3} \\
\mathrm{~m}_{4}
\end{array}\right)
$$

$$
\mathbf{x}=\mathbf{A} \cdot \mathbf{m} .
$$

These equations are called observation equations. If the elements of matrix $\mathbf{A}$, which is called the design matrix, are determined, we can calculate $\mathbf{m}$, i.e., the volume proportion of minerals. The method used to determine the design matrix is presented below. The program to solve the set of equations can be written easily with computer software for numerical computation; we wrote the program with MATLAB (Version 5.2; The MathWorks, Inc.), which is excellent in matrix computation.

\section{Determination of design matrix}

If only quartz occupies a certain pixel, equation (4) will be represented as

$$
\left(\begin{array}{l}
\mathrm{x}_{1} \\
\mathrm{x}_{2} \\
\mathrm{x}_{3} \\
\mathrm{x}_{4} \\
\mathrm{x}_{5}
\end{array}\right)=\left(\begin{array}{llll}
\mathrm{A}_{11} & \mathrm{~A}_{12} & \mathrm{~A}_{13} & \mathrm{~A}_{14} \\
\mathrm{~A}_{21} & \mathrm{~A}_{22} & \mathrm{~A}_{23} & \mathrm{~A}_{24} \\
\mathrm{~A}_{31} & \mathrm{~A}_{32} & \mathrm{~A}_{33} & \mathrm{~A}_{34} \\
\mathrm{~A}_{41} & \mathrm{~A}_{42} & \mathrm{~A}_{43} & \mathrm{~A}_{44} \\
\mathrm{~A}_{51} & \mathrm{~A}_{42} & \mathrm{~A}_{43} & \mathrm{~A}_{54}
\end{array}\right) \cdot\left(\begin{array}{l}
1 \\
0 \\
0 \\
0
\end{array}\right)=\left(\begin{array}{l}
\mathrm{A}_{11} \\
\mathrm{~A}_{21} \\
\mathrm{~A}_{31} \\
\mathrm{~A}_{41} \\
\mathrm{~A}_{51}
\end{array}\right) .
$$

These measured values $\left(\mathrm{x}_{i}\right)$ specifically correspond to the first column of the design matrix. Measuring a standard sample of quartz within the same image would enable us to determine the first column of the design matrix. Alternatively, we estimate an average value in quartz-occupied pixels sampled from the Si map. This is simple because grain size is larger than the pixel size $(1$ pixel $=96 \times 96 \mu \mathrm{m})$. The other columns also were determined in the same way. The average values for plagioclase-, K-feldspar- and annite-occupied pixels were obtained from the $\mathrm{K}, \mathrm{Ca}$ and $\mathrm{Fe}$ maps, respectively. Since some bias can be generated by human analysis, we used several tens (annite) or several hundreds (the other minerals) of pixels from several distinct grains to make the design matrix as average as possible. For example, the design matrix (A) and its standard deviation $\left(\Sigma_{\mathbf{A}}\right)$ for operation time of 48 hours were obtained as follows.

$\begin{aligned} \mathrm{A} & =\left(\begin{array}{cccc}1.9 & 5.1 & 9.7 & 5.0 \\ 109.7 & 34.2 & 62.3 & 30.3 \\ 3.4 & 5.6 & 166.9 & 100.9 \\ 1.5 & 40.7 & 19.7 & 12.8 \\ 24.7 & 50.6 & 26.9 & 1924.0\end{array}\right) . \\ \Sigma_{\mathrm{A}} & =\left(\begin{array}{cccc}1.3 & 3.4 & 3.0 & 2.1 \\ 14.9 & 11.1 & 11.2 & 10.7 \\ 3.6 & 3.3 & 25.4 & 18.1 \\ 1.6 & 19.1 & 5.8 & 3.2 \\ 23.0 & 48.9 & 23.0 & 223.8\end{array}\right) .\end{aligned}$

The design matrix varied with operation time, and its elements were found to be proportional to operation time (Fig. 2).

\section{The solution of observation equations}

The Maximum Likelihood (ML) method is usually used for the solution of observation equations like equation (4). The practical algorithm of the ML method is distinguished by a parent distribution, from which the 

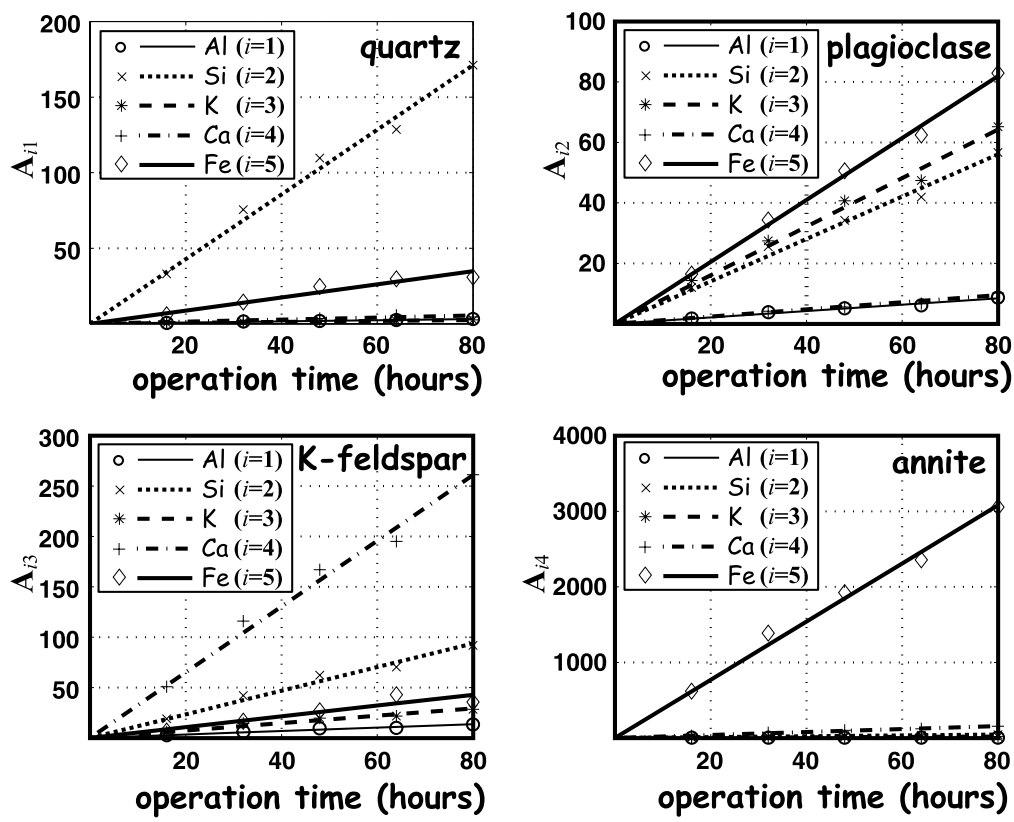

FIG. 2. Relationship between each element of the design matrix and operation time of the SXAM. $\mathrm{A}_{i j}$ expresses each element of the matrix. The $i$ denotes a row subscript, and the $j$, a column subscript. The points such as circles and crosses, etc., represent the estimated values, and the lines are fitted by the least-squares method. It is clear that any element is directly proportional to the operation time.

measured data are sampled. In our case, a Poisson distribution was generally adopted for such photon-count data. Hence, we will first consider the ML method for the Poisson distribution.

In the ML method, the unknown quantities $\left(\mathrm{m}_{j}\right)$ are determined as the likelihood function $\mathrm{L}$ is maximized:

$$
L=\prod_{i=1}^{5} \frac{f_{i}}{x_{i} !} \exp \left(-f_{i}\right)
$$

where $f_{i}=\sum_{j=1}^{4} A_{i j} m_{j}$. Then, the following equations must be solved, where the partial derivative of the logarithm of $\mathrm{L}$ with respect to $\mathrm{m}_{j}$ equals zero. That is:

$$
\sum_{i=1}^{5} \frac{x_{i}-f_{i}}{f_{i}} \frac{\partial f_{i}}{\partial m_{j}}=0 \quad(j=1,2,3,4) .
$$

It is, however, impossible to solve equation (7) analytically because of its nonlinearity. A powerful computational environment is necessary to solve this expression.
This approach is not consistent with one of our aims: easy analysis on a personal computer. If one were compelled to use an ordinary personal computer (Pentium II $266 \mathrm{MHz}, \mathrm{RAM}-64 \mathrm{MB}$ ) to solve these equations, it would take several months to compute the solution for $256 \times 256$ pixels. Therefore, it would be of no practical use.

Alternatively, if the measured intensity is comparatively large (generally over 20 counts or so), a Gaussian distribution can be adopted instead of the Poisson distribution. Then the equations corresponding to equation (6) and (7) are represented as

$$
L=\left(\frac{1}{2 \pi}\right)^{\frac{5}{2}} \prod_{i=1}^{5}\left(\frac{1}{\sigma_{i}}\right) \exp \left\{-\frac{1}{2} \sum_{i=1}^{5} \frac{\left(x_{i}-f_{i}\right)^{2}}{\sigma_{i}^{2}}\right\}
$$

$$
\sum_{i=1}^{5} \frac{x_{i}-f_{i}}{\sigma_{i}^{2}} \frac{\partial f_{i}}{\partial m_{j}}=0 \quad(j=1,2,3,4),
$$

respectively, where $\sigma_{i}^{2}$ is an unbiased variance of $\mathrm{x}_{i}$. This method corresponds to the so-called weighted least-squares method. Moreover, it is possible to solve 

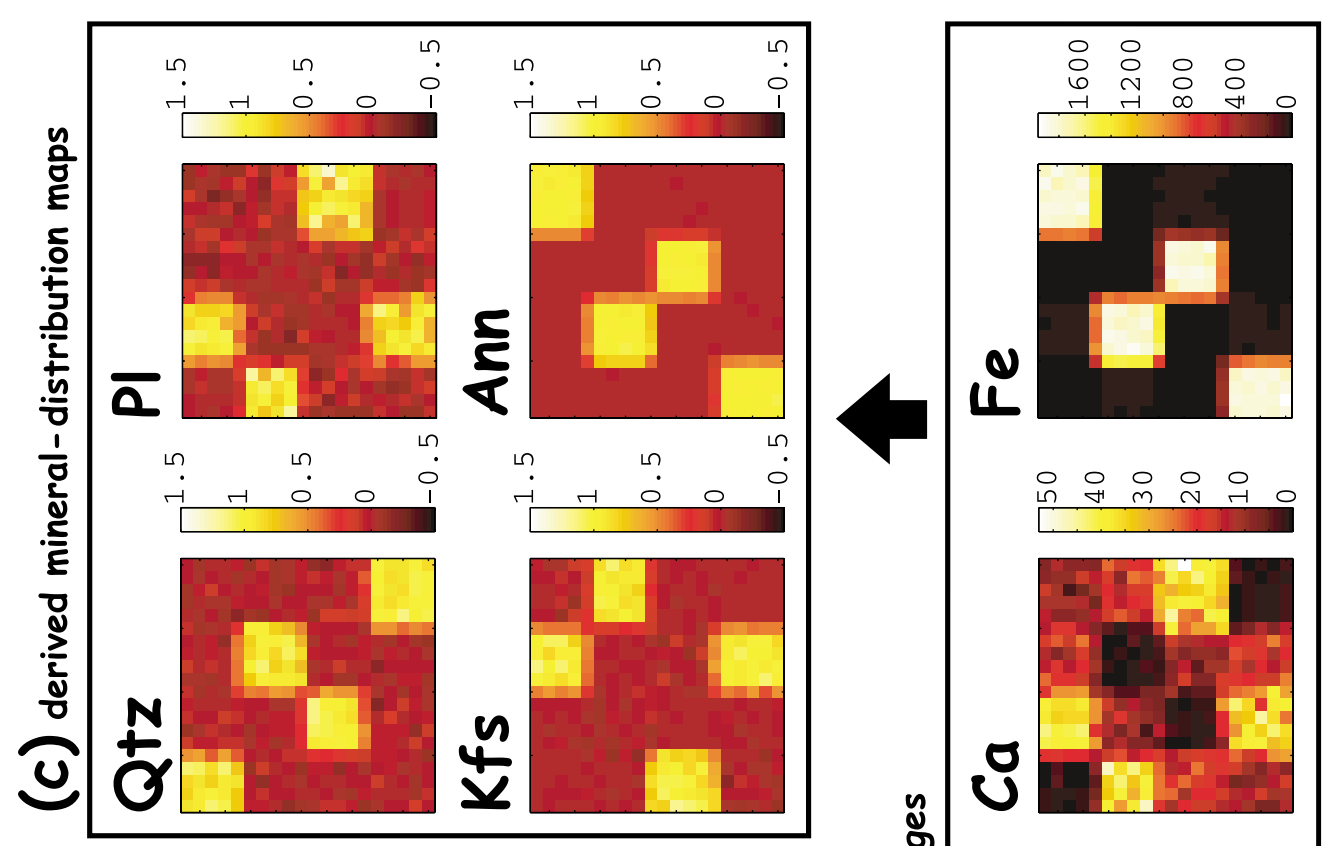

章 蛋

要专

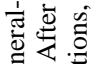

हैं

घ

突

高弯离

읭

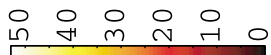

के

औ 3 के

罗颌

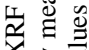

两要

要

‥?

ใ.

중

急完

势

焉

\%

覀

욜

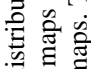
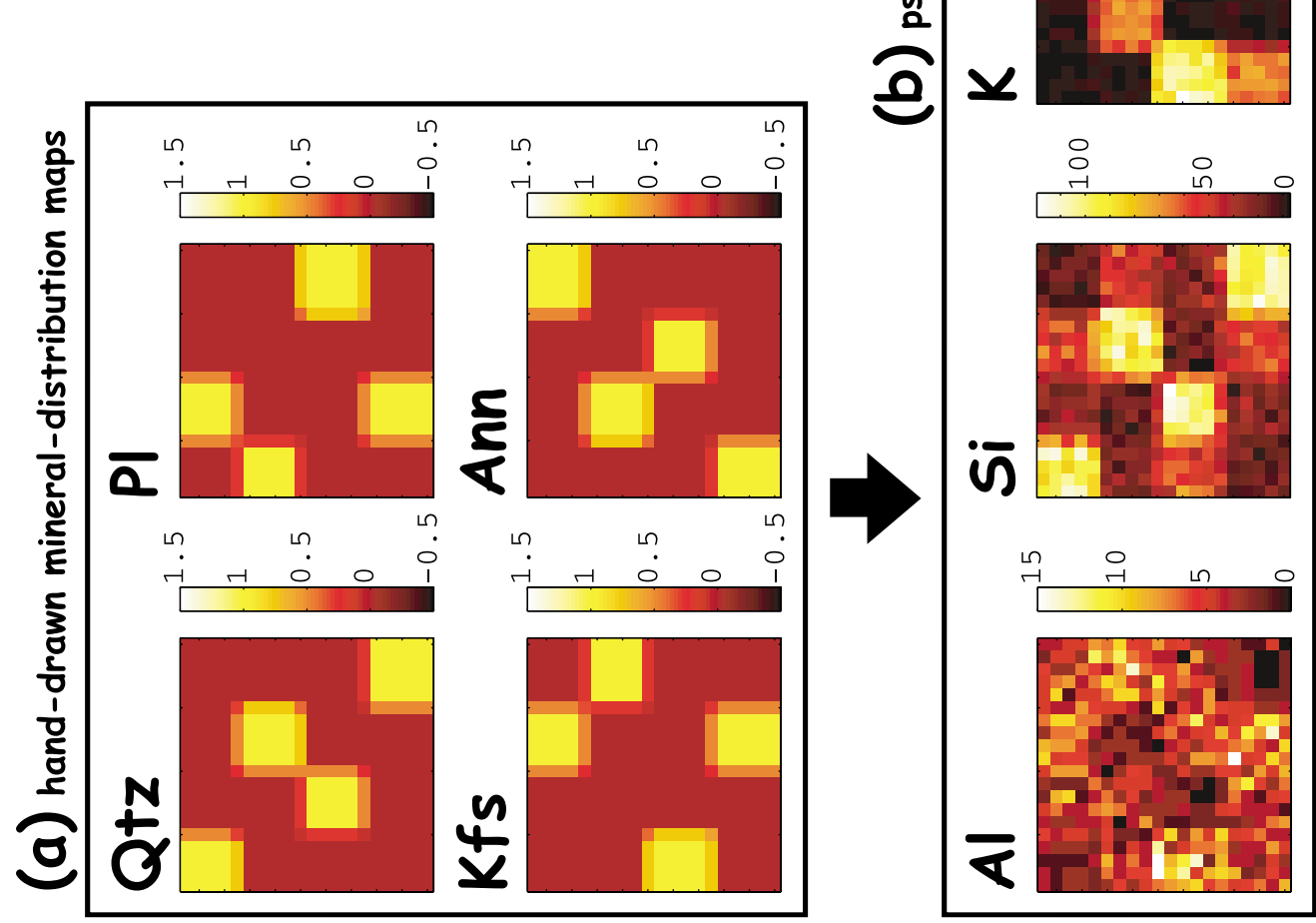

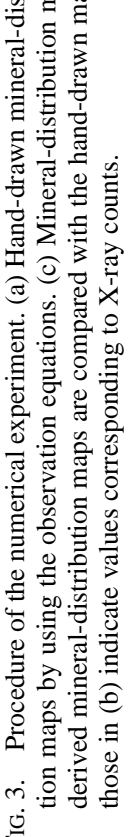


equation (9) analytically. If these equations are solved by a personal computer, it will take only several tens of minutes. As the increment of $\mathrm{X}$-ray intensities is achieved by expansion of the operation time of XRF images, we performed a numerical experiment to determine the operation time required to adopt the weighted least-squares method.

\section{Numerical experiment}

First, hand-drawn mineral-distribution maps of $20 \times 20$ pixels were prepared (Fig. 3a). Next, a value corresponding to the mean amount of X-ray counts was computed at every pixel using equation (4), in which the elements of the design matrix were obtained from the lines in Figure 2. A value randomly sampled from the "Poisson distribution", whose mean was the computed value using equation (4), was used as a value corresponding to the X-ray counts in pseudo-XRF images. The pseudo-XRF images for an operation time of 48 hours are shown in Figure $3 \mathrm{~b}$. Then we transformed the pseudo-XRF images to mineral-distribution maps by the "weighted least-squares method" (Fig. 3c). In order to compare the derived mineral-distribution maps (Fig. 3c) with the original maps (Fig. 3a), we calculated the correlation coefficient $\mathrm{R}$ of every mineral as

$$
R=\frac{\sum_{k=1}^{20} \sum_{l=1}^{20}\left\{y_{0}(k, l)-y_{0 m}\right\}\left\{y(k, l)-y_{m}\right\}}{(20 \times 20) \sqrt{\sigma_{0}^{2} \sigma^{2}}},
$$

where $\mathrm{y}_{0}(\mathrm{k}, \mathrm{l})$ is a volume population on the coordinate $(\mathrm{k}, \mathrm{l})$ in any of the original mineral-distribution maps, $\mathrm{y}_{0 \mathrm{~m}}$ is the mean of $\mathrm{y}_{0}, \mathrm{y}(\mathrm{k}, \mathrm{l})$ is the volume population on the coordinate $(\mathrm{k}, \mathrm{l})$ in any of the derived mineral-distribution maps, $\mathrm{y}_{\mathrm{m}}$ is the mean of $\mathrm{y}, \sigma_{0}^{2}$ is an unbiased variance of $\mathrm{y}_{0}$, and $\sigma^{2}$ is an unbiased variance of $y$. The more $\mathrm{R}$ approaches 1 , the better the derived mineraldistribution maps resemble the original maps; in other words, the better the mineral-distribution maps are restored. Figure 4 shows the relationship between operation time and the correlation coefficient (R). It is clear that $\mathrm{R}$ is above 0.96 for an operation time of 48 hours or more for any mineral. We therefore conclude that the measured values for 48 hours or more operation are trustworthy even though a weighted least-squares method was performed.

\section{Mineral-distribution maps derived for the granite}

Figure 5a shows the mineral-distribution maps processed from the XRF images for an operation time of 48 hours. Each map presents estimated proportions of a mineral. Where only one mineral occurs in a pixel, its estimated proportion has a value of 1 , whereas the other minerals in the same pixel have a value of 0 . In the case of pixels on grain boundaries of different minerals, estimated proportions for that pixel have values between 0 and 1 . In any case, the sum of quantities in each pixel from the mineral-distribution maps is equal to one, as expected according to the method. However, some pixels rarely have values that are greater than 1 or are smaller than 0 . These abnormal values appear particularly in the mineral-distribution map for plagioclase (Fig. 5a). As described below, they are derived from some inevitable errors.

The least-squares method has the great advantage of revealing the distribution of a single mineral quantitatively. However, one may wish to view the distributions of all minerals in a single map. In this way, the processed mineral maps can be combined into a single map. Figure $5 b$ is such an example, in which the mineral selected has the highest proportion in each pixel. It is important to note that such a map is less quantitative than the mineral-distribution maps in Figure 5a, because the former eliminates the information of minor minerals from pixels that contain more than one mineral.

\section{DISCUSSION}

\section{Estimation of error}

The grain sizes within the granite studied in this paper are larger than the size of a pixel. It is therefore expected that the mineral populations have peaks around either 0 or 1, or both, as each pixel should represent only one mineral. However, individual pixels within the mineral-distribution maps in Figure 5a include some abnormal values, as pixels have values less than 0 or more than 1. For example, the black areas in the plagioclase map indicate negative quantities of plagioclase. These

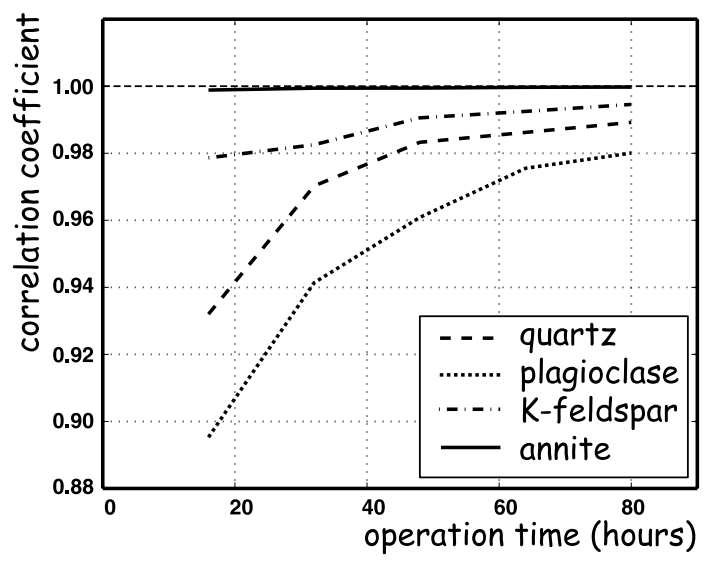

FIG. 4. Relationship of the correlation coefficient between each hand-drawn mineral-distribution map (Fig. 3a) and each map derived by the analysis (Fig. 3c) to the SXAM operation time. 

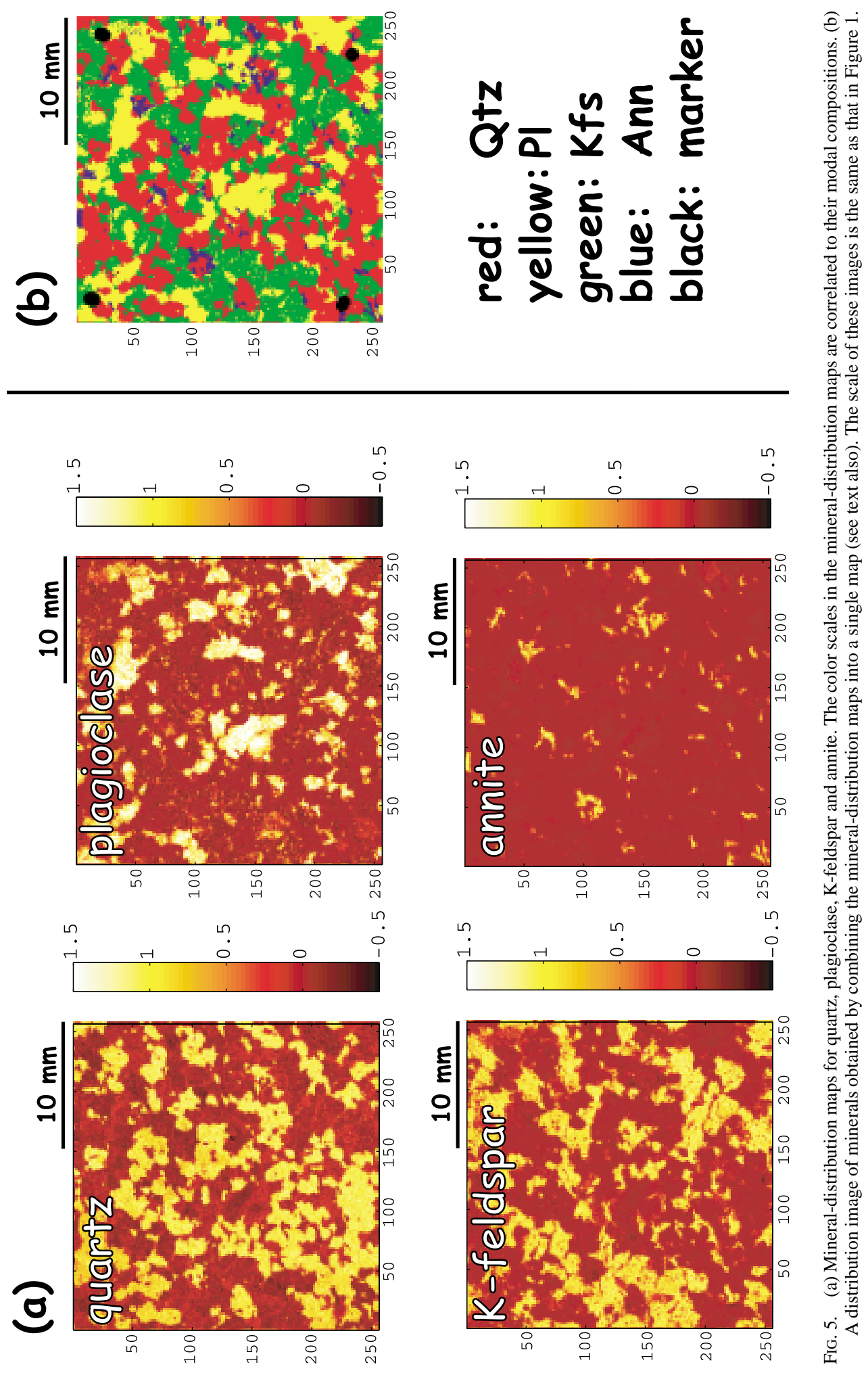
abnormal values could result from either (1) a mistake in the algorithm or (2) inevitable instability in this analysis, or both of these. The former possibility can be examined by a $\chi^{2}$ test, which is one of the most common tests in statistics. As a result, it shows that about $4 \%$ of all pixels only were involved in the critical region (significance level: 0.01). Therefore, we believe that the algorithm does not contribute significantly to abnormal values. The latter could result from fluctuation of X-ray intensity that necessarily occurs in detecting X-rays, variation of chemical composition for each mineral, condition of the sample's surface, or the influence of accessory minerals other than the four main minerals. For instance, X-ray counts of Si never have exactly a constant value, even if only pure quartz were analyzed under the same condition. Thus, the estimated proportion of quartz may possibly result in a value more than 1 .
This means that we cannot eliminate abnormal values unless X-ray counts are perfectly stable.

Alternatively, since the standard deviations of the design matrix $\left(\Sigma_{\mathbf{A}}\right)$ include all such errors, we define an error of the estimated mineral proportion in each pixel in Figure $5 \mathrm{a}$ as a standard deviation derived from $\Sigma_{\mathrm{A}}$ by the propagation law of errors. Note that the $\sigma_{i}^{2}$ values in equation (9) are obtained by transforming the $\Sigma_{\mathbf{A}}$ into the $\sigma_{i}{ }^{2}$. Figure 6 shows maps for the standard deviations for individual minerals, where a value in each pixel represents the standard deviation for the value in the same pixel of minerals in Figure 5a. For example, the abnormal values appear particularly in the mineral map for plagioclase, whose chemical composition is more varied than the other minerals, so that their standard deviations are also very large. As a consequence, the derived mineral-distribution maps have some errors, as pixels
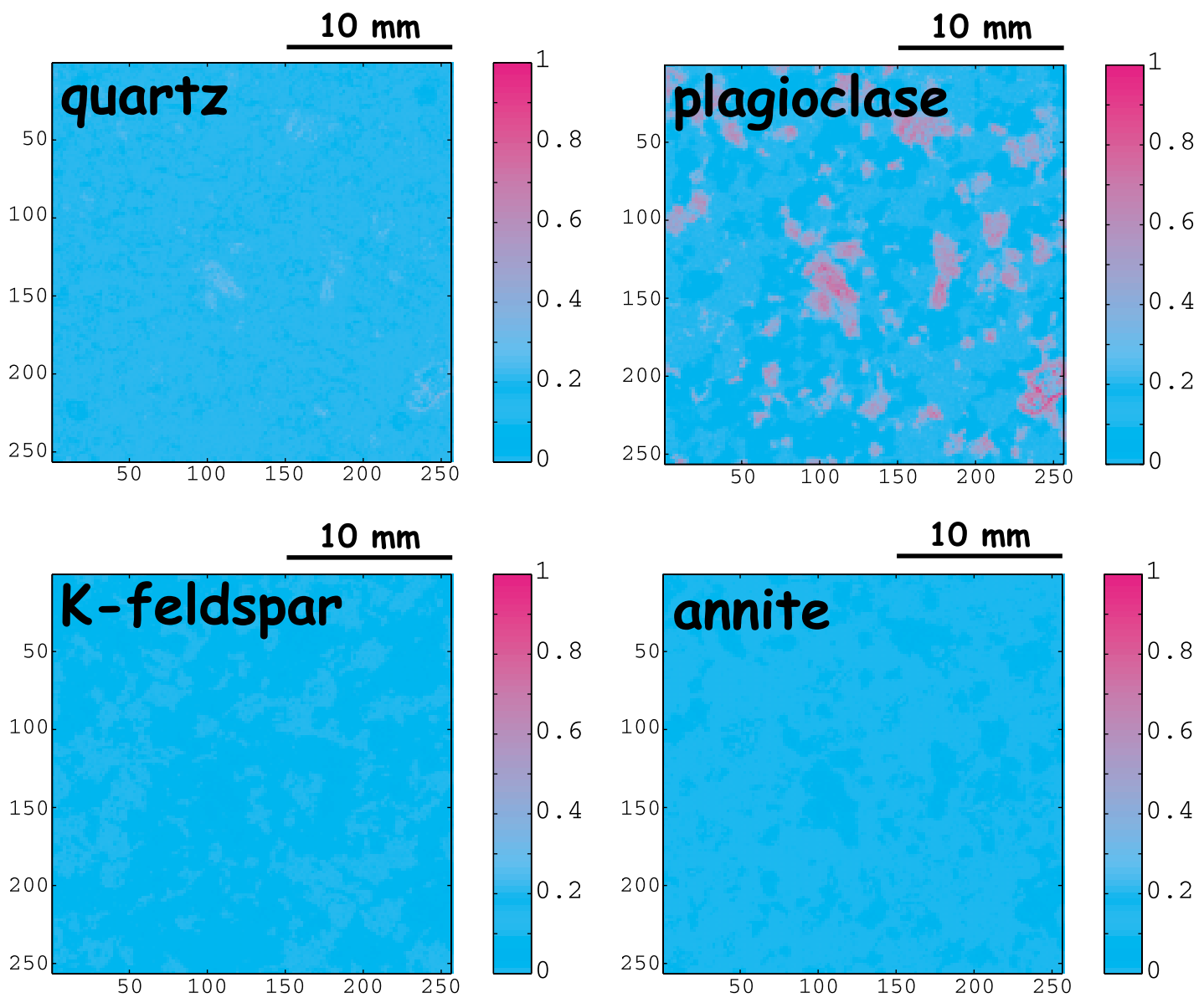

FIG. 6. Standard deviation maps for each mineral-distribution maps (Fig. 5a). A value in each pixel represents the standard deviation for the value in the same pixel of minerals in Figure 5a. 
with negative concentrations of a mineral, but still give a satisfactory distribution of the minerals of interest where they do exist.

\section{Limitations of the method}

Since elements lighter than aluminum cannot be detected by the SXAM, the minerals at present that can be measured are restricted to some extent. The number of mineral species must be also smaller than the number of elemental species in order to use the observation equations. Where one mineral shows evidence of variable chemical composition, such as plagioclase in this study, its XRF intensity becomes considerably unstable, so that the computed proportion of that mineral may be erroneous. Finally, measured X-ray intensity changes with the grain size of the minerals, even if the chemical composition remains the same. This phenomenon could be significant where the grain size is small (e.g., $\leq 1 \mathrm{~mm}$; Claisse \& Samson 1962).

\section{ConClusion}

We have developed a method in which the XRF images produced by the SXAM are transformed into mineral-distribution maps. This method is useful if the mineral composition is simple (such as granite) and if the SXAM is operated for suitable times. The error in the computed proportions of minerals was also estimated. The algorithm shown in this paper can be adapted to analyze images produced with other instruments, such as EPMA and SEM-EDX.

\section{ACKNOWLEDGEMENTS}

We thank Drs. S. Kawakami, H. Yoshioka, T. Okaniwa, H. Yamagishi, M. Murakami and N. Sugimoto for providing constructive comments, and Prof. T. Bell of James Cook University (Australia) and Dr. A.R. Stallard of Shizuoka University for improving the English in this paper. We also thank the referees, Drs. P. Launeau and R. Lastra, for reading the manuscript and giving useful comments. We are indebted to the editor, R.F. Martin, for improving the manuscript. This research was supported by a Grant-in-Aid for Scientific Research in the priority areas of the Ministry of Education, Japan (the Decoding Earth Evolution Program) to M. Takano and M. Kumazawa, JSPS Research Fellowships for Young Scientists to S. Togami, and Grant-inAids for Scientific Research from the Ministry of Education to M. Takano and K. Michibayashi.

\section{REFERENCES}

ArITA, M. (1988): Petrographical studies on granitic rocks in the Kojima Peninsula and Shiwaku Islands, the central parts of Seto Inland Sea, Southwest Japan: proterogenetic and magmatogenetic origin of granitic rocks. J. Geol. Soc. Japan 94, 279-293 (in Japanese with English abstr.).

Chiarutini, C., Schena, G., Ramponi, G. \& Kröner, S. (1999): Automated segmentation of SEM images for phase measurement. Trans. IMM (in press).

Claisse, F. \& Samson, C. (1962): Heterogeneity effects in xray analysis. In Advances in X-Ray Analysis 5. Plenum Press, New York, N.Y. (335-354).

Dilks, A. \& GRAHAM, S.C. (1985): Quantitative mineralogical characterization of sandstones by back-scattered electron image analysis. J. Sed. Petrol. 55, 347-355.

HaLl, M.G. \& LLOYD, G.E. (1981): The SEM examination of geological samples with a semiconductor back-scattered electron detector. Am. Mineral. 66, 362-368.

HAYASHI, T. \& SUZUKI, M. (1990): Modal analysis of granitic rocks by image processing on a personal computer. J. Mineral. Petrol. Econ. Geol. 85, 60-65 (in Japanese with English abstr.).

Hosokawa, Y., OZawa, S., Nakazawa, H. \& Nakayama, Y. (1997): An X-ray guide tube and a desk-top scanning Xray analytical microscope. $X$-ray Spectrom. 26, 380-387.

Ikeda, S., Nakashima, S. \& Tsuchiyama, A. (1997): Image analysis of rocks textures - present status and problems in its automation. J. Mineral. Soc. Japan 26, 185-196 (in Japanese with English abstr.).

Lastra, R., Petruk, W. \& Wilson, J. (1998): Image analysis techniques and applications to minerals processing. In Modern Approaches to Ore and Environmental Mineralogy (L.J. Cabri \& D.J. Vaughan, eds.). Mineral. Assoc. Can., Short Course 27, 327-366.

Launeau, P., Cruden, A.R. \& Bouchez, J.-L. (1994): Mineral recognition in digital images of rocks: a new approach using multichannel classification. Can. Mineral. 32, 919-933.

Michibayashi, K., Togami, S., Takano, M., Kumazawa, M. \& Kageyama, T. (1999): Application of scanning X-ray analytical microscope to the petrographic characterization of a ductile shear zone: an alternative method to image microstructures. Tectonophys. 310, 55-67.

Miller, R.P., Reid, A.F. \& Zuderwyk, M.A. (1982): QEM*SEM image analysis in the determination of modal assays, mineral association and mineral liberation. Proc. XIV Int. Mineral Processing Congress (Toronto), Can. Inst. Mining Metall., Pap. VIII-3.

Nishimoto, S. (1996): Modal analysis of granitic rocks by a personal computer using image processing software "Adobe Photoshop"TM". J. Mineral. Petrol. Econ. Geol. 91, 235-241 (in Japanese with English abstr.).

PetruK, W. (1988): Capabilities of the microprobe Kontron image analysis system: application to mineral beneficiation. Scanning Microscopy 2, 1247-1256. 
(1989): Image analysis of minerals. In Image Analysis Applied to Mineral and Earth Sciences (W. Petruk, ed.). Mineral. Assoc. Can., Short Course 16, 6-18.

PYE, K. (1984): Rapid estimation of porosity and mineral abundance in backscattered electron images using a simple SEM image analyser. Geol. Mag. 121, 81-84.

Robinson, B.W. \& Nickel, E.H. (1979): A useful new technique for mineralogy: the backscattered-electron / low vacuum mode of SEM operation. Am. Mineral. 64, 13221328 .

Tsuchiyama, A., Kitamura, M., Ohbori, K., Shibata, H. \& Hosokawa, Y. (1991): Multielement EDX mapping of meteorites. Proc. NIPR Symp. on Antarctic Meteorites 4, 115-118.

WILSON, J.M.D. \& LASTRA, R. (1999): Quantification of silicate minerals by SEM-based image analysis. In Analytical Technology in the Mineral Industries: Proc. of the TMS Symposium (L.J. Cabri, C.H. Bucknam, E.B. Milosavljevic, S.L. Chryssoulis \& R.A. Miller, eds.). The Minerals, Metals \& Materials Society, San Diego, California (151163).

Received April 5, 2000, revised manuscript accepted July 17, 2000. 